\title{
Host adaptations in the fixLJ pathway of the Burkholderia cepacia complex increase virulence
}

Matthew M. Schaefers ${ }^{1,2 *}$, Benjamin X. Wang ${ }^{3}$, Nicole M. Boisvert ${ }^{1}$, Sarah J. Martini ${ }^{1}$, Sarah L. Bonney ${ }^{1}$, Christopher W. Marshall ${ }^{4 \#}$, Michael T. Laub ${ }^{3,5}$, Vaughn S. Cooper ${ }^{4}$, Gregory P. Priebe ${ }^{1,2}$

1 Division of Critical Care Medicine, Department of Anesthesiology, Critical Care and Pain Medicine, Boston Children’s Hospital; Boston, MA, USA.

2 Harvard Medical School, Boston, MA, USA.

3 Department of Biology, Massachusetts Institute of Technology, Cambridge, MA USA

4 Microbiology and Molecular Genetics, University of Pittsburgh, Pittsburgh, PA, USA

5 Howard Hughes Medical Institute, Massachusetts Institute of Technology, Cambridge, MA, USA

\# Present Address: Department of Biological Sciences, Marquette University, Milwaukee, WI, USA

* Corresponding author

E-mail: matthew.schaefers@childrens.harvard.edu (MS)

\begin{abstract}
The Burkholderia cepacia complex (BCC) is composed of multiple species, including $B$. multivorans and $B$. dolosa, that are significant pathogens for people with cystic fibrosis (CF) and are extensively resistant to many antibiotics. The fixL gene of the fixLJ 2component system (TCS) in these BCC species shows evidence of positive selection for nonsynonymous mutations during chronic lung infection in CF. Previous work showed that the $B$. dolosa fix $L J$ system regulates $11 \%$ of the genome and modulates biofilm formation, motility, persistence within macrophages, and virulence in a murine pneumonia model. Here, we assess the impacts of clinically observed FixL evolved variants in fixLJ pathway-mediated phenotypes in B. dolosa and B. multivorans. BCC carrying the ancestral fixL sequence are less pathogenic than constructs carrying evolved variants in both a macrophage infection model and a murine pneumonia model. In vitro phospho-transfer experiments demonstrate that the evolved $B$. dolosa FixL variants are able to reduce fixLJ pathway activity by either having lower levels of kinase activity or increased phosphatase activity. Notably, the ancestral fixL genotype has increased ability to survive within the soil compared to isogenic constructs with evolved fixL genotypes, demonstrating that increased virulence comes at an expense. Modulation of the FixLJ system has profound effects on many BCC phenotypes including full pathogenicity, and this modulation is critical for BCC adaptation to the host.
\end{abstract}




\section{Main}

The Burkholderia cepacia complex (BCC) is a group of more than 20 species of closelyrelated Gram-negative bacilli that can be dangerous respiratory pathogens for people with cystic fibrosis (CF). ${ }^{1,2}$ Among CF patients in the US colonized with BCC, the species most commonly seen are $B$. cenocepacia and $B$. multivorans, although there is significant variability based on geographic region and institution, ${ }^{3-7}$ and $B$. multivorans has emerged as the most predominant $\mathrm{BCC}$ species infecting $\mathrm{CF}$ patients in some regions. ${ }^{4-7} \mathrm{BCC}$ members have caused several outbreaks within the CF community, ${ }^{2}$ including one outbreak of a highly antibiotic-resistant strain of $B$. dolosa among almost $40 \mathrm{CF}$ patients in Boston ${ }^{8}$ and another of B. cenocepacia in Toronto. ${ }^{9}$ BCC can also cause serious infections in individuals with chronic granulomatous disease (CGD). ${ }^{10}$ Outbreaks of hospital-acquired BCC infections in non-CF and non-CGD patients have also been increasingly described, often associated with contaminated medications, ${ }^{11-16}$ including a recent outbreak associated with contamination of the stool softener docusate with $B$. contaminans. ${ }^{15,16}$

Analysis of genomic diversity arising during $B$. dolosa and B. multivorans chronic infections in CF identified the fixL $J$ two-component system (TCS) as a pathway that is under positive selection, evident from enrichment for non-synonymous mutations as opposed to synonymous mutations and genetic parallelism among many independent infections. ${ }^{17-19}$ TCSs are one mechanism that bacteria use to sense and respond to their environment. ${ }^{20}$ Our previous work determined that the fix $L J$ pathway senses oxygen tension, is important for virulence in a murine model of pneumonia, and regulates $\sim 11 \%$ of the genome. ${ }^{21}$ Additionally we found that the fix $L J$ system is involved in biofilm formation and motility as $B$. dolosa lacking fix $L J$ made more biofilm and had reduced motility. ${ }^{21}$ The $f i x L J$ system was also critical for survival within THP-1-dervived human macrophages. These experiments were conducted using a fixLJ deletion mutant to determine the effects of deletion of both genes. In the current study, we found, that constructs carrying clinically observed FixL variants (single amino acid changes) were more virulent, had altered gene expression, and were less able to survive within soil that isogenic constructs carrying ancestral FixL variants. These results highlight the importance of the FixLJ pathway in BCC pathogenesis and provide insight into the evolution of $\mathrm{BCC}$ during chronic infection.

\section{Results}

Mutations in BCC FixL sensory domain are associated with decline in lung function. In a series of published works, involving more than $100 \mathrm{~B}$. dolosa longitudinal isolates taken over 16 years from 14 different CF patients and $22 \mathrm{~B}$. multivorans isolates taken from a single CF patient over 20 years, we identified mutations within fix $L J$ during chronic lung infection. ${ }^{17-19}$ The locations of these mutations within the predicted domains of FixL are depicted in Figure 1A. Most mutations are within the predicted PAS and PAC domains, which are conserved sensory domains. ${ }^{22}$ Based on our previous work ${ }^{21}$ and the predicted heme-binding pocket, it appears that the BCC fix $L J$ pathway is an oxygensensing mechanism. Of note, the FixL proteins of $B$. dolosa (AK34_969) and $B$. multivorans (BMD20_10585) share 98\% protein identity. 
We compared the lung function of patients from our previous study ${ }^{18}$ who were infected with $B$. dolosa isolates containing FixL sequence variants to determine if there was a correlation between FixL sequence variants and clinical outcomes. An increased rate of decline in lung function, measured by percent predicted FEV1 (ppFEV1), in patient L after $B$. dolosa isolates with mutations in the predicted sensory domain (red arrows) was detected. This slope differs in comparison to earlier time points, before such mutations were detected (Figure 1B, purple and green arrows, red versus blue line: $\mathrm{P}=0.05$ comparing slopes using linear regression). The single green arrow among the purple arrows demonstrates that multiple lineages coexisted at the same time in the lung ${ }^{17}$. Another patient, patient M, who lacked isolates mutated in the predicted FixL sensory domain, had a more modest decline in lung function over a similar period.

To determine the specific phenotypes of evolved FixL alleles, we generated isogenic constructs in reference isolate $B$. dolosa AU1058. The fix LJ deletion strain ${ }^{21}$ was complemented with the ancestral FixL sequence (W439) or the evolved sequence found in strain AU0158 (W439S). It is worth pointing out that the reference strain AU0158 is an evolved strain as it was isolated $\sim 3$ years after initial $B$. dolosa infection. Strains containing the FixL sequence variants that were associated with lower lung function in Figure 1B were also generated: G345S and R347H, and both constructs had the ancestral tryptophan, $\mathrm{W}$, at residue 439 . These constructs were also complemented with the conserved ancestral sequence of FixJ, along with $\sim 600$ base pairs upstream allowing for expression from its native promoter, using a mini-Tn7 based vector allowing for longterm stability without the need for selection by the insertion into the chromosome. ${ }^{23} \mathrm{We}$ also compared the effects that FixL sequence variants have on virulence in B. multivorans by generating isogenic variants within $B$. multivorans VC7102 (BM2) by replacing a fragment of the fixL gene in its native location with a fragment with the desired evolved mutation. ${ }^{24}$

\section{BCC strains carrying evolved FixL variants are more virulent in human macrophages and a murine pneumonia model but less able to survive in soil.}

We compared the ability of BCC constructs carrying FixL sequence variants to survive within the THP-1 human monocyte cell line treated with PMA to differentiate into macrophage-like cells. B. dolosa constructs carrying the evolved FixL variant (W439S) and the evolved variants associated with a period of clinical decline (G345S and R347H) were significantly better able to survive at 2-3-fold higher levels compared to constructs carrying ancestral variant (W439) or lacking fixLJ (empty vector) (Figure 2A). One of the two B. multivorans evolved variants, FixL T353M, had increased survival within THP-1dervived macrophages compared to the ancestral strain (VC7102) (Figure 2B).

Our previous work found a correlation between the ability to survive within THP1-dervived macrophages and the ability to persist within murine lungs and to disseminate and persist with the spleen after intranasal inoculation. ${ }^{21}$ In order to measure the ability of the constructs to persist in vivo, C57BL/6 mice were intranasally infected with these BCC constructs using similar methods. Mice infected with $B$. dolosa carrying the evolved (reference) FixL variant (W439S) had 4-5-fold higher levels of bacteria within the lungs and spleen compared to mice infected with $B$. dolosa carrying the ancestral FixL variant (W439) or lacking fixLJ (empty vector) (Figure 2C). Mice that were infected with $B$. multivorans VC7102 carrying the evolved FixL variant that conferred increased survival 
within THP-1-dervived macrophages (T353M) had significantly increased bacterial loads with the lungs and the spleen compared to mice infected with bacteria carrying the ancestral sequence variant or the other evolved variant not associated with increased survival in THP-1-dervived macrophages (R400G) (Figure 2D).

To determine if the fixL mutations that confer an increased level of virulence within the host came with an expense in ability to survive within soil, a natural ecological niche of BCC, we measured the ability of the different constructs to survive within soil for 10 days. We found that all three evolved FixL variants (W439S, G345S, and R347H) had a 5-6-fold reduction in the ability to survive within soil compared to the ancestral variant (W439) (Figure 2E). Bacteria lacking fixLJ were also less able to survive within the soil, demonstrating the importance of the fix pathway to survival both within the host and in the environment.

\section{BCC strains carrying evolved FixL variants are more motile, make less biofilm, and have altered gene expression.}

Our previous work showed that $B$. dolosa lacking fix $L J$ produced increased levels of biofilm and had decreased motility. ${ }^{21}$ We found that both $B$. dolosa and B. multivorans carrying evolved FixL alleles produced significantly less biofilm than isogenic strains carrying the ancestral FixL sequence (Figure 3A and 3B). B. dolosa and B. multivorans constructs carrying evolved FixL sequence variants also had increased motility compared constructs carrying the ancestral variant (Figure 3C and 3D). Interestingly, $B$. dolosa carrying the ancestral FixL variant was completely non-motile, the diameter plotted in Figure $3 \mathrm{C}(\sim 12 \mathrm{~mm})$ was the diameter of the $10 \mu \mathrm{L}$ drop placed on the agar surface. $B$. dolosa carrying an empty vector which lacks fix $L J$ still had the ability to swim albeit at lower levels (Figure 3C).

To identify the differentially expressed genes that were responsible for the various observed phenotypes, we measured global transcript levels using RNA-seq (Supplemental Table 1). Previously we found that $\sim 11 \%$ of the genome was differentially expressed in a $B$. dolosa fix $L J$ deletion mutant. ${ }^{21}$ There were 205 genes that were significantly downregulated and 302 genes significantly upregulated ( $q$ value $<0.05$, at least 2-fold difference) in B. dolosa carrying evolved FixL variant W439S (Figure 3E) compared to $B$. dolosa carrying the ancestral FixL W439. We analyzed for Gene Ontology (GO) terms that were enriched among the genes that were significantly differentially expressed. Surprisingly, there were no GO terms that were enriched among genes that were upregulated in B. dolosa carrying the ancestral FixL W439. However, there were four GO terms that were enriched among genes that were differentially expressed in B. dolosa carrying the evolved variant (FixL W439S, Figure 3F). Three of these GO terms are associated with motility or chemotaxis, and the fourth is associated with signal transduction. A subset of the genes associated with motility and flagellar assembly that were differentially up-regulated in $B$. dolos $a$ carrying the evolved variant (FixL W439S) are listed in Table 1. We confirmed the differential levels of $f l i C$ and $m o t A$ transcripts in B. dolosa carrying the ancestral FixL variant (W439), evolved FixL variant (W439S), and empty vectors using qRT-PCR (Supplemental Figure 1).

Among the genes that were differentially regulated we identified several differentially expressed genes that have homologs identified in other bacteria that play a role in c-di-GMP metabolism (Supplemental Table 2). This expression pattern suggests 
that there may be a decrease in intracellular c-di-GMP levels in the evolved variants and this may explain the increased motility and decreased biofilm seen in these constructs. ${ }^{25}$

${ }^{27}$ Notably a homolog of the predicted phophodiesterase $c p d A$ that could hydrolyze c-diGMP, AK34_1958, was significantly downregulated in $B$. dolosa carrying the ancestral FixL variant ( $\sim 8.5$ fold, Table S2). B. pseudomalle $i^{26}$ and B. cenocepacia ${ }^{27,28}$ mutants lacking $\operatorname{cpd} A$ had reduced motility consistent with the $B$. dolosa carrying the ancestral FixL variant which had lower $c p d A$ transcript levels and lower motility. Similar to $B$. pseudomallei and B. cenocepacia cpdA, B. dolosa AU0158 cpdA has predicted GGDEF and EAL domains, but only the EAL domain is predicted to be enzymatically active based on amino acid sequence at the catalytic site. B. pseudomalle ${ }^{26}$ and $B$. cenocepacia ${ }^{28}$ mutants lacking $c p d A$ had increased levels c-di-GMP, but, surprisingly, there was a significant increase in intracellular c-di-GMP levels found in the $B$. dolosa construct carrying the evolved FixL variant (Supplemental Figure 2).

Table 1. Selected genes associated with motility and/or flagellar assembly that are significantly differentially expressed in $B$. dolosa carrying evolved FixL sequence variant (W439S) relative $B$. dolosa carrying evolved FixL ancestral variant, W439.

\begin{tabular}{|l|l|r|}
\hline $\begin{array}{l}\text { Gene name } \\
\text { genome } \\
\text { designation) }\end{array}$ & Description & $\begin{array}{l}\text { Fold change in B. dolosa } \\
\text { carrying evolved FixL } \\
\text { sequence variant W439S }\end{array}$ \\
\hline AK34_2913 & Flagellin protein FliC & 205.8 \\
\hline AK34_2901 & Flagellar motor rotation protein MotA & 46.8 \\
\hline AK34_2900 & Flagellar motor rotation protein MotB & 19.9 \\
\hline AK34_2902 & Flagellar transcriptional activator FlhC & 24.9 \\
\hline AK34_2903 & Flagellar transcriptional activator FlhD & 10.9 \\
\hline AK34_2914 & Flagellar cap protein FliD & 22.7 \\
\hline AK34_2885 & Flagellar biosynthesis protein FlhA & 46.5 \\
\hline AK34_2886 & Flagellar biosynthesis protein FlhB & 28.1 \\
\hline AK34_83 & $\begin{array}{l}\text { Flagellar basal-body P-ring formation } \\
\text { protein FlgA }\end{array}$ & 18.2 \\
\hline AK34_86 & $\begin{array}{l}\text { Flagellar basal-body rod modification } \\
\text { protein FlgD }\end{array}$ & 49.8 \\
\hline AK34_87 & Flagellar hook protein FlgE & 32.0 \\
\hline AK34_88 & Flagellar basal-body rod protein FlgF & 22.7 \\
\hline AK34_2914 & Flagellar cap protein FliD & 17.2 \\
\hline AK34_3043 & Flagellar motor switch protein FliM & 9.0 \\
\hline AK34_3044 & Flagellar motor switch protein FliN & \\
\hline
\end{tabular}

\section{Evolved FixL variants have different mechanisms of down-regulating fix pathway activity.}

Most TCS function by regulating gene expression when activated by a specific signal. The first component, the sensor kinase, senses the signal and autophosphorylates. The phosphate is then transferred to the second component, the response regulator, which can then regulate gene transcription. ${ }^{20}$ We conducted in vitro phosphorylation assays with recombinant FixL and FixJ proteins to measure the ability of the different FixL variants 
to phosphorylate themselves and then subsequently, FixJ. We hypothesized that FixL variants that had different phenotypes would have differing levels of autophosphorylation and/or phosphotransfer. Figure 4A shows that the ancestral FixL W439 had higher levels of autophosphorylation compared to the evolved FixL W439S. When the levels of autophosphorylation were quantified, the evolved FixL W439S had approximately 50\% the level of autophosphorylation of the ancestral sequence (Figure 4B). Interestingly the other two evolved variants, G345S and R347H, also had similar levels of autophosphorylation compared to the ancestral variant (Figure 4A and 4B) despite making less biofilm and being more motile like the other evolved variant, W439S. Equal amounts of each of the purified protein were used in each reaction and each protein preparation was $>90 \%$ pure (Supplemental Figure 3). When the autophosphorylation levels were quantified relative to the 1-minute time point, only the W439S autophosphorylation levels decreased while the other three variants increased or stayed the same (Supplemental Figure 4). We also measured the ability of the recombinant FixL variants to phosphorylate the response regulator FixJ. As the evolved variant W439S had lower levels of autophosphorylated FixL, that variant had lower levels of phosphotransfer to FixJ compared to the ancestral variant W439 (Figure 4C and 4D). When the level of phosphotransfer to FixJ was quantified relative to level of autophosphorylated FixL, the evolved variant W439S had a different profile compared to the ancestral variant and the other two evolved variants. The W439S had a more rapid phosphotransfer to FixJ and a greater level of dephosphorylation of FixJ (Figure 4D).

Both of the other two evolved variants G345S and R347H had high initial levels of phosphotransfer (Figure 4C), but at later time points R347H had lower levels of phosphorylated FixJ compared to the ancestral FixL W439 suggesting R347H had increased levels of phosphatase activity. To confirm the downregulation of the fix pathway in an evolved variant, we measured fix activity using a $B$. dolosa fixK promoterdriven LacZ reporter plasmid using the pSCrhaB2 backbone. ${ }^{21}$ We found that both the ancestral (W439) and the evolved (W439S) FixL variants had an increase in fix pathway activity when the construct was grown in low oxygen $(<5 \%)$, demonstrating that both variants are activated in oxygen tension (Figure 4E). Consistent with the in vitro phosphorylation experiments, the ancestral FixL (W439) had higher fix activity than the evolved variant (W439S) when grown in either ambient or low oxygen.

\section{Discussion}

Previous work has determined that the BCC fixLJ system shows evidence of positive selective pressure during chronic lung infection in CF patients ${ }^{17-19}$ and is critical for BCC virulence. ${ }^{21}$ In this study we evaluated the function of evolved FixL sequence variations in both $B$. dolosa and $B$. multivorans by generating isogenic constructs carrying the evolved FixL variants. These evolved FixL variants were more virulent, more motile, and produced less biofilm. The FixL mutations that occurred during chronic infection downregulated the fix signaling cascade, demonstrating that high fix activity is detrimental for virulence (Figure 4). Interestingly, different FixL variants had different mechanisms of downregulating fix pathway activity, including decreases in autophosphorylation and increases in phosphatase activity. 
We found that BCC carrying ancestral fixL sequences had reduced motility and reduced virulence in both murine and macrophage models compared to variants carrying evolved sequences (Figures 2 and 3 ) suggesting that the reduced motility was contributing to the reduced virulence, as has been suggested by other studies. ${ }^{29-31}$ Our previous work demonstrated that $B$. dolosa lacking flagella were equally virulent as parental, flagellated strains, suggesting motility plays a minimal role in the infection models evaluated. ${ }^{21}$ We analyzed the transcriptome of $B$. dolosa constructs carrying ancestral or evolved FixL variants to understand the mechanisms of the altered phenotypes seen between the two constructs. Among the genes that were identified to be differentially expressed between $B$. dolosa carrying different fix $L$ sequences were genes that have homologs in other bacterial species that are involved in c-di-GMP metabolism (Supplemental Table 2). ${ }^{25-27}$ Surprisingly, B. dolosa carrying the ancestral FixL sequence that made increased levels of biofilm had lower levels of c-di-GMP than B. dolosa carrying the evolved FixL sequence variant (Figure S2). The increased biofilm seen in $B$. dolosa carrying the ancestral FixL sequence variant and in B. dolosa lacking fixLJ was independent of increased c-di-GMP levels, indicating that there are additional pathways involved in biofilm formation. Furthermore, high levels of c-di-GMP have been shown to stimulate the production of extracellular polysaccharides that leads to increased biofilm formation. ${ }^{27,32}$ Interestingly, the genes that are responsible for c-di-GMP induced production of polysaccharides (Bep, PNAG, and cepacian) ${ }^{33-35}$ were not differentially expressed by RNA-seq analysis (Supplemental Table 1) suggesting that c-di-GMPindependent mechanisms of biofilm production are involved.

One potential c-di-GMP-independent mechanism of biofilm production involves the wsp system that can promote biofilm formation in B. cenocepacia without direct activation of a diguanylate cyclase. ${ }^{36,37}$ Multiple components of the $w s p$ system were 2-4fold up-regulated in B. dolosa carrying ancestral FixL (Supplemental Table 2), suggesting a potential role of the wsp system in fix pathway-mediated biofilm formation. The contribution of biofilm formation to $\mathrm{BCC}$ virulence remains unclear, as constructs carrying ancestral FixL sequences produced more biofilm and were less pathogenic in our murine model of pneumonia than isogenic constructs carrying evolved FixL variants (Figures 2 and 3). Similarly in our previous study, B. dolosa fix LJ deletion mutants made more biofilm and were less pathogenic than the parental strain that contained fixLJ. ${ }^{21}$ These findings suggesting that BCC biofilms may not be beneficial for infection are supported by a study of CF lung explants from patients infected with $P$. aeruginosa and/or BCC and stained using species-specific antibodies. ${ }^{38}$ BCC bacteria were rarely found in biofilm-like structures while $P$. aeruginosa were often found in such structures, suggesting BCC do not form biofilms during infection. The conversion of BCC from a mucoid, biofilm-producing state to a non-mucoid phenotype is often observed during chronic infection and is correlated with worse clinical outcomes (notably different from $P$. aeruginosa, where mucoid strains are associated with clinical decline).${ }^{39}$ Interestingly, these more virulent isolates are found early during infection for $P$. aeruginosa but are found later during infection for CF patients infected with BCC. ${ }^{39,40}$

Since increased biofilm formation is not associated with increased $\mathrm{BCC}$ virulence (Figures $2 \& 3$ ), we hypothesized that biofilm formation may allow for the $B$. dolosa to better survive within the soil. But the ability to make biofilms does not, on its own, confer the ability to survive within soil as $B$. dolosa lacking fix $L J$ was unable to persist in 
the soil at high levels (Figure 4) despite making higher levels of biofilm (Figure 3). The mutations in fix $L J$ that confer increased virulence are likely dead-end mutations as they make the bacteria less able to survive within the natural BCC reservoir. It is possible that these mutations make the bacteria more transmissible between human hosts -- future work will investigate this.

To better understand the mechanism of altered phenotypes seen in the constructs carrying different FixL variants we examined genes that had the largest magnitude of differential expression by RNA-seq. One such gene is an AraC family transcription regulator (AK34_4608) that was significantly downregulated ( 95 fold) in B. dolosa carrying the evolved FixL variant (Supplemental Table 2). Expression of this gene is potentially detrimental to bacterial dissemination since a homolog of this gene was found to be downregulated in blood B. cenocepacia isolates taken from $\mathrm{CF}$ patients with cepacia syndrome compared to lung isolates taken at same time. ${ }^{41}$ Additionally, a homolog of this same gene was found to be downregulated in B. pseudomallei isolates from CF patients taken at late versus early time points. ${ }^{42}$ Another set of genes that were differentially expressed encode a putative CidA/CidB-like, holin/anti-holin system (AK34_3040, AK34_3041) that was significantly downregulated ( 64- and 42-fold, respectively) in $B$. do $\overline{\text { losa }}$ carrying the evolved FixL variant (Supplemental Table 2). Homologs of this system were found to up-regulated in $P$. aeruginosa when grown in vitro with Staphylococcus aureus, ${ }^{43}$ suggesting that upregulation of this system may result in more autolysis and increased biofilm formation. ${ }^{44}$ Further investigation is needed to determine the role of these genes in $\mathrm{BCC}$ virulence and their role in fix pathwaymediated phenotypes.

In this study, we have characterized the effects of mutations within the oxygensensing two-component system fix $L J$ system that arise during chronic infection in people with CF. Some of these mutations were associated with a period of clinical decline. Isogenic constructs carrying these evolved FixL sequence variants were more virulent, more motile, and produced less biofilm. Multiple studies have investigated the genetic and phenotypic changes that occur within $P$. aeruginosa and to a lesser extent BCC. ${ }^{45-47}$ During chronic infection, $P$. aeruginosa becomes less motile, produces more biofilm, shows increased antibiotic resistance, and has increased auxotrophy, ultimately leading to the evolution of reduced virulence of late isolates in animal models of infection. ${ }^{45,46}$ Less is known about phenotypic changes that occur during chronic BCC infection, and most prior work has focused on B. cenocepacia. ${ }^{48}$ The findings from this study demonstrate a novel way $\mathrm{BCC}$ adapt to the host by making the bacteria more pathogenic at the cost of being less able to survive within the environment.

\section{Methods \\ Clinical data}

Records of $B$. dolosa-infected patients were reviewed under Boston Children's Hospital IRB protocol number M10-08-0370.

\section{Bacterial strains, plasmids, cell lines, and growth conditions}

All strains used and generated in this study are listed in Table 2. B. dolosa strain AU0158 was obtained from Dr. John LiPuma (University of Michigan) and is an early isolate from the index patient from the $B$. dolosa outbreak (about 3 years into the 
outbreak). BCC and E. coli were grown on LB plates or in LB medium and supplemented with following additives: ampicillin $(100 \mu \mathrm{g} / \mathrm{mL})$, kanamycin $(50 \mu \mathrm{g} / \mathrm{mL}$ for E. coli, 1 $\mathrm{mg} / \mathrm{mL}$ for BCC), trimethoprim $(100 \mu \mathrm{g} / \mathrm{mL}$ for $E$. coli, $1 \mathrm{mg} / \mathrm{mL}$ for BCC), gentamicin (15 or $50 \mu \mathrm{g} / \mathrm{mL})$, chloramphenicol $(20 \mu \mathrm{g} / \mathrm{mL})$, or diaminopimelic acid $(200 \mu \mathrm{g} / \mathrm{mL})$. Plasmids that were used in this study are listed in Table 3. Human monocyte line THP-1 was obtained from ATCC and grown at $37^{\circ} \mathrm{C}$ with $5 \% \mathrm{CO}_{2}$. THP-1 cells were cultured in RPMI-1640 medium containing $2 \mathrm{mM}$ L-glutamine, $10 \mathrm{mM}$ HEPES, $1 \mathrm{mM}$ sodium pyruvate, $4500 \mathrm{mg} / \mathrm{L}$ glucose, and $1500 \mathrm{mg} / \mathrm{L}$ sodium bicarbonate, supplemented with $10 \%$ heat-inactivated FCS (Invitrogen) and $0.05 \mathrm{mM}$ 2-mercaptoethanol. Low-oxygen environments were generated by the CampyGen Gas Generating System (ThermoFisher), and the low-oxygen concentration $(<5 \%)$ is based on the manufacture specifications. 
Table 2. Strains used in this study.

\begin{tabular}{|c|c|c|}
\hline & Notes & Source \\
\hline \multicolumn{3}{|l|}{ E.coli } \\
\hline $\begin{array}{l}\text { NEB 5-alpha Competent } E \text {. } \\
\text { coli }\end{array}$ & DH5 $\alpha$ derivative cloning strain & NEB \\
\hline RHO3 & 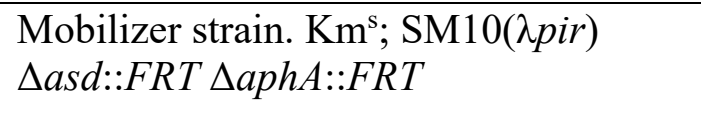 & 24 \\
\hline BL21 (DE3) & Protein expression strain & Invitrogen \\
\hline \multicolumn{3}{|l|}{$\mathrm{BCC}$} \\
\hline B. dolosa AU0158 & Clinical isolate & $\begin{array}{l}\text { John } \\
\text { LiPuma }\end{array}$ \\
\hline B. multivorans VC7102 & Clinical isolate & \begin{tabular}{|l|}
19 \\
\end{tabular} \\
\hline$\Delta f i x L J+\mathrm{W} 439 \mathrm{~S}$ fixLJ & $\begin{array}{l}\text { B. dolosa } \Delta f i x L J+\text { pfixLJ carrying } \\
\text { W439S FixL and FixJ, integrated at } \\
\text { attTn7 site downstream of AK34_4894 }\end{array}$ & 21 \\
\hline$\Delta f i x L J+$ Empty Vector & $\begin{array}{l}\text { B. dolosa } \Delta \text { fix LJ + empty pUC18T- } \\
\text { mini-Tn7T-Tp integrated at attTn7 site } \\
\text { downstream of AK34_4894 }\end{array}$ & 21 \\
\hline$\Delta f i x L J+\mathrm{W} 439$ fix $L J$ & $\begin{array}{l}\text { B. dolosa } \Delta \text { fix } L J+\mathrm{p} \text { p } i x L J \text { carrying } \\
\text { W439 FixL and FixJ, integrated at } \\
\text { att } \operatorname{Tn} 7 \text { site downstream of AK34_4894 }\end{array}$ & This study \\
\hline$\Delta f i x L J+\mathrm{R} 347 \mathrm{H}$ fixLJ & $\begin{array}{l}\text { B. dolosa } \triangle \text { fixLJ + pfixLJ carrying } \\
\text { R347H FixL and FixJ, integrated at } \\
\text { attTn7 site downstream of } \\
\text { AK34_4894 }\end{array}$ & This study \\
\hline$\Delta$ fixLJ + G345S fixLJ & $\begin{array}{l}\text { B. dolosa } \Delta \text { fixLJ + pfixLJ carrying } \\
\text { G345S FixL and FixJ, integrated at } \\
\text { attTn7 site downstream of } \\
\text { AK34_4894 }\end{array}$ & This study \\
\hline VC7102 (FixL T353M) & $\begin{array}{l}\text { VC7102 with T353M mutation in native } \\
\text { fixL gene using pBM_FixL_T353M }\end{array}$ & This study \\
\hline VC7102 (FixL R400G) & $\begin{array}{l}\text { VC7102 with R400G mutation in native } \\
\text { fixL gene using pBM_FixL_R400G }\end{array}$ & This study \\
\hline $\begin{array}{l}\Delta f i x L J+\text { W439S fixLJ / } \\
\text { pfixK-reporter }\end{array}$ & $\begin{array}{l}\text { B. dolos a } \triangle \text { fix } L J \text { complemented with } \\
\text { W439S fix } J \text { carrying } \mathrm{p} \text { fixK -reporter }\end{array}$ & 21 \\
\hline$\Delta f i x L J+\mathrm{EV} / \mathrm{p} f i x K$-reporter & $\begin{array}{l}\text { B. dolosa } \Delta \text { fix } L J \text { complemented with } \\
\text { empty vector carrying p } f i x K \text {-reporter }\end{array}$ & 21 \\
\hline $\begin{array}{l}\Delta f i x L J+\mathrm{W} 439 \text { fixLJ / p fixK } \\
\text {-reporter }\end{array}$ & $\begin{array}{l}\text { B. dolosa } \triangle \text { fix } L J \text { complemented with } \\
\text { W43S fix } L J \text { carrying p fixK -reporter }\end{array}$ & This study \\
\hline
\end{tabular}


Table 3. Plasmids used in this study.

\begin{tabular}{|c|c|c|}
\hline & Notes & Source \\
\hline $\mathrm{pEXkm5}$ & $\mathrm{Km}^{\mathrm{R}}, s a c B, g u s A$ & 24 \\
\hline pTNS3 & $\begin{array}{l}A m p^{\mathrm{R}} \text {, helper plasmid for } \\
\text { mini-Tn7 integration into } \\
\text { att } \operatorname{Tn} 7 \text { site }\end{array}$ & 49 \\
\hline pRK2013 & $\mathrm{Km}^{\mathrm{R}}$ conjugation helper & 50 \\
\hline pSCrhaB2 & $\mathrm{Tp}^{\mathrm{R}}$, ori $i_{\mathrm{pBBR} 1}$ rhaR, rhaS & 51 \\
\hline pUC18T-mini-Tn7T-Tp & $\begin{array}{l}A m p^{\mathrm{R}}, \mathrm{Tp}^{\mathrm{R}} \text { on mini-Tn7T; } \\
\text { mobilizable }\end{array}$ & 50 \\
\hline $\mathrm{p}$ fix LJ-W439S & $\begin{array}{l}\text { pUC18T-mini-Tn7T-Tp } \\
\text { carrying W439S FixL and } \\
\text { FixJ with } 670 \text { upstream } \\
\text { flanking }\end{array}$ & 21 \\
\hline $\mathrm{p}$ fix LJ-W439 & $\begin{array}{l}\text { pUC18T-mini-Tn7T-Tp } \\
\text { carrying W439 FixL and } \\
\text { FixJ with } 670 \text { upstream } \\
\text { flanking }\end{array}$ & This study \\
\hline $\mathrm{p}$ fixLJ-R347H & $\begin{array}{l}\text { pUC18T-mini-Tn7T-Tp } \\
\text { carrying R347H FixL and } \\
\text { FixJ with } 670 \text { upstream } \\
\text { flanking }\end{array}$ & This study \\
\hline $\mathrm{p} f$ ix LJ-G345S & $\begin{array}{l}\text { pUC18T-mini-Tn7T-Tp } \\
\text { carrying G345S FixL and } \\
\text { FixJ with } 670 \text { upstream } \\
\text { flanking }\end{array}$ & This study \\
\hline pBM_FixL_T353M & $\begin{array}{l}\text { pEXkm5 containing } 1.5 \\
\mathrm{kbp} \text { fragment encoding } \\
\text { T353M FixL mutation }\end{array}$ & This study \\
\hline pBM_FixL_R400G & $\begin{array}{l}\text { pEXkm5 containing } 1.5 \\
\text { kbp fragment encoding } \\
\text { R400G FixL mutation }\end{array}$ & This study \\
\hline $\mathrm{p}$ fixK -reporter & $\begin{array}{l}\text { pSCrhaB2 carrying } B . \\
\text { dolosa fixK-lacZ fusion } \\
\text { with } \mathrm{Km}^{\mathrm{R}} \text { in place of } \mathrm{Tp}^{\mathrm{R}}\end{array}$ & 21 \\
\hline pENTR & $\begin{array}{l}\text { Gateway cloning entry } \\
\text { vector }\end{array}$ & Invitrogen \\
\hline pTRX-HIS-DEST & $\begin{array}{l}\text { Expression vector for } \\
\text { Response regulator Amp }\end{array}$ & 52 \\
\hline pHIS-MBP-DEST & $\begin{array}{l}\text { Expression vector for } \\
\text { Histidine Kinase Amp }\end{array}$ & 52 \\
\hline pENTR-FixJ & $\begin{array}{l}\text { B. dolosa AU0158 fixJ } \\
\text { cloned into pENTR }\end{array}$ & This study \\
\hline
\end{tabular}




\begin{tabular}{|l|l|l|}
\hline pENTR-FixL & $\begin{array}{l}\text { B. dolosa AU0158 fixL } \\
\text { AA 329-851 cloned into } \\
\text { pENTR }\end{array}$ & This study \\
\hline pFixJ_Expression & $\begin{array}{l}\text { B. dolosa fixJ cloned into } \\
\text { pTRX-HIS-DEST for } \\
\text { purification }\end{array}$ & This study \\
\hline pFixL_W439_Expression & $\begin{array}{l}\text { B. dolosa fixL containing } \\
\text { W439 sequence cloned } \\
\text { into pHIS-MBP-DEST for } \\
\text { purification }\end{array}$ & This study \\
\hline pFixL_W439S_Expression & $\begin{array}{l}\text { B. dolosa fixL containing } \\
\text { W439S sequence cloned } \\
\text { into pHIS-MBP-DEST for } \\
\text { purification }\end{array}$ & \\
\hline pFixL_R347H_Expression & $\begin{array}{l}\text { B. dolosa fixL containing } \\
\text { R347H sequence cloned } \\
\text { into pHIS-MBP-DEST for } \\
\text { purification }\end{array}$ & \\
\hline pFixL_G345S_Expression & $\begin{array}{l}\text { B. dolosa fixL containing } \\
\text { G345S sequence cloned } \\
\text { into pHIS-MBP-DEST for } \\
\text { purification }\end{array}$ & \\
\hline
\end{tabular}

\section{Genetic Manipulations and Strain Construction}

To generate $B$. dolosa constructs carrying fix $L$ mutations, we introduced the desired mutations using the Q5 Site-Directed Mutagenesis Kit (New England Biolabs) into $\mathrm{p}$ fix $K .^{21} \mathrm{p}$ fixK contains the AU0158 fix LJ sequence along with 670 bp upstream within the pUC18-mini-Tn7-Tp back bone allowing for stable chromosomally integration at an att $\operatorname{Tn} 7$ site. $^{23,50}$ Point mutations were verified by Sanger sequencing. The $B$. dolosa fix $L J$ complementation vectors and the corresponding empty vector controls were conjugated into the AU0158 fixLJ deletion mutant with pRK2013 and pTNS3 using published procedures. ${ }^{21}$ Conjugants were selected for by plating on LB agar containing trimethoprim $(1 \mathrm{mg} / \mathrm{mL})$ and gentamicin $(50 \mu \mathrm{g} / \mathrm{mL})$. Insertions into the att $\operatorname{Tn} 7$ site downstream of AK34_4894 was confirmed by PCR. To generate B. multivorans VC7102 constructs carrying fix $\bar{L}$ mutations, we introduced the desired fix $L$ mutations in the native fixL gene using the suicide plasmid pEXKm5. ${ }^{24}$ Briefly, approximately $1 \mathrm{kbp}$ upstream and downstream of the desired mutation was PCR amplified, as was pEXKm5, and then the two fragments were joined using the NEBuilder HiFi DNA Assembly Master Mix (NEB) per manufacturer's protocol. The plasmids were Sanger sequenced and transformed into RHO3 E. coli and then conjugated into B. multivorans VC7102. ${ }^{23,49}$ Conjugants were selected for on LB with kanamycin at $1 \mathrm{mg} / \mathrm{mL}$. To resolve merodiploidy, conjugants were counterselected against by plating on LB with $15 \% \mathrm{w} / \mathrm{v}$ sucrose and incubated for 2 days at $30^{\circ} \mathrm{C}$. Clones were screened for the introduction of desired mutation by PCR and Sanger sequencing. 
Expression vectors for FixL and FixJ His6-tagged proteins were generated using the Gateway high-throughput recombinational cloning system (Invitrogen). The entire fixJ gene or fixL amino acids 329-851 (lacking transmembrane domains) were amplified from B. dolosa AU0158 and cloned in pENTR. Gateway LR clonase reactions were used to move fixL or fixJ into pHIS-MBP-DEST or pTRX-HIS-DEST, respectively, for expression. ${ }^{52}$ fixL mutations were introduced using Q5 Site-Directed Mutagenesis Kit (New England Biolabs) and sequences were confirmed by Sanger sequencing. To generate fix $K$ reporter strains a fixK-lac $Z$ fusion reporter was conjugated into $B$. dolosa constructs as previously described. ${ }^{21}$

\section{Bacterial invasion assays}

The ability of $B$. dolosa to invade and persist within macrophages was determined using published protocols. ${ }^{21}$ Human THP-1 monocytes were differentiated into macrophages by seeding $1 \mathrm{~mL}$ into 24 -well plates at $8 \times 10^{5}$ cells $/ \mathrm{mL}$ with $200 \mathrm{nM}$ phorbol 12 -myristate 13-acetate (PMA). THP-1 derived macrophages were infected with log-phase grown BCC washed in RPMI three times at $\sim 2 \times 10^{6} \mathrm{CFU} /$ well (MOI of $\sim 10: 1$ ). Plates were spun at $500 \mathrm{~g}$ for 5 minutes to synchronize infection and then incubated for 2 hours at $37^{\circ} \mathrm{C}$ with $5 \% \mathrm{CO}_{2}$. To determine the total number of bacteria, wells were treated with $100 \mu \mathrm{L}$ of 10\% Triton-X100 lysis buffer (final concentration 1\% Triton-X100), serially diluted, and plated to enumerate the number of bacteria. To determine the number of intracellular bacteria, separate infected wells were washed two times with PBS and then incubated with RPMI $+10 \%$ heat-inactivated FCS with kanamycin $(1 \mathrm{mg} / \mathrm{mL})$ for 2 hours. Monolayers were washed three times with PBS and lysed with 1\% Triton-X100, serially diluted, and plated to enumerate the number of bacteria.

\section{Murine model of pneumonia}

All animal protocols and procedures were approved by the Boston Children's Hospital Institutional Animal Care and Use Committee (assurance number A3303-01). The specific protocol number is 18-01-3617R. All animal protocols are compliant with NIH Office of Laboratory Animal Welfare, Guide for the Care and Use of Laboratory Animals, The US Animal Welfare Act, and PHS Policy on Humane Care and Use of Laboratory Animals. Female C57BL/6 mice 6-8 weeks of age were obtained from Taconic Biosciences. Mice were maintained at the animal facilities at Boston Children's Hospital. Mice were anesthetized with ketamine $(100 \mathrm{mg} / \mathrm{kg})$ and xylazine $(13.3 \mathrm{mg} / \mathrm{kg})$ given intraperitoneally. While the mice were held in dorsal recumbency, $10 \mu \mathrm{L}$ of inoculum was instilled in each nostril $(20 \mu \mathrm{L}$ total $)$. The inoculum consisted of log-phase B. dolosa washed in PBS and diluted to a concentration of $\sim 2 \times 10^{10} \mathrm{CFU} / \mathrm{mL}\left(4 \times 10^{8}\right.$ $\mathrm{CFU} /$ mouse). Mice were euthanized 7 days after infection by $\mathrm{CO}_{2}$ overdose, when lungs and spleen were aseptically removed. Lungs and spleens were weighed and placed into 1 $\mathrm{mL} 1 \%$ proteose peptone in water, homogenized, and then serially diluted and plated on Oxidation/Fermentation-Polymyxin-Bacitracin-Lactose (OFPBL) plates.

\section{Biofilm formation}

The ability to form biofilm on PVC plates was determined using published methods. ${ }^{53}$ Briefly, overnight cultures were diluted in Trypticase Soy Broth (TSB) with 1\% glucose and pipetted into wells of a 96-well PVC plate. Plates were incubated 48 hours at $37^{\circ} \mathrm{C}$, 
when unattached bacteria were washed with water. Biofilms were stained with $0.5 \%$ crystal violet and excess stain was washed away, and stain was solubilized with $33 \%$ acetic acid. The solution was transferred to a flat bottom plate, and then biofilm amount was quantified by measuring $\mathrm{OD}_{540}$.

\section{Motility assay}

The ability of $B$. dolosa to swim was measured in low density LB agar using published methods. ${ }^{54}$ Briefly, $10 \mu \mathrm{L}$ of overnight $B$. dolosa culture was plated in the center of low density $\left(0.3 \%\right.$ agar) LB plate. Plates were incubated agar side down for 48 hours at $37^{\circ} \mathrm{C}$ when swimming diameter was measured.

\section{RNA-seq}

RNA was isolated from log-phase $B$. dolosa (two biological replicates per construct) using the Ribopure Bacterial RNA Purification Kit (Ambion) per manufacturer's protocol, and contaminant DNA was removed using DNase. RNA was processed and libraries generated as previous published. ${ }^{21}$ Samples were sequenced using single end 50 bp reads using the Illumina HiSeq platform. Data analysis was done using Galaxy (usegalaxy.org). ${ }^{55}$ Reads (9-12 million reads per replicate) were trimmed using the Trimmomatic tool ${ }^{56}$ and mapped to the B. dolosa AU0158 genome (GenBank assembly accession GCA_000959505.1) ${ }^{57}$ using BowTie2 with very sensitive local preset settings. ${ }^{58}$ Differentially expressed genes were identified using CuffDiff using Benjamini-Hochberg procedure to determine the q value ( $p$ value corrected for multiple comparisons). ${ }^{59}$ Reads were deposited to BioProject PRJNA579568. GO terms that were enriched among genes that were differentially regulated were identified using GoSeq, using a Wallenius approximation and a Benjamini-Hochberg to determine a corrected pvalue for multiple comparisons. ${ }^{60} \mathrm{GO}$ terms that were considered to be enriched had and adjusted $p$ value $<0.05$.

\section{qRT-PCR}

cDNA was synthesized from $2 \mu \mathrm{g}$ RNA using the ProtoScript II First Strand cDNA Synthesis Kit (NEB) per manufacture's protocol. cDNA was cleaned using QIAquick PCR Purification Kit (Qiagen). Oligos to amplify $g y r B$, $r p o D$, and $f l i C$ were previously published, ${ }^{21}$ and mot $A$ was amplified using 5'- GTGAAGATCGGGCTCTTGT-3' and 5'GGACGTCTATATGGAGCTGATG-3'. Genes were amplified using oligos FastStart Essential DNA Green Master Mix (Roche) per manufacturer's protocol. Expression was determined relative to $B$. dolosa AU0158 carrying the W439S FixL variant normalized by gyrB (AK34_3072) or $r p o D$ (AK34_4533) expression using the $\Delta \Delta \mathrm{Ct}$ method. ${ }^{61}$ Both gyr $B$ and $r p o D$ had similar expression by RNA-seq between AU0158 and the fix LJ deletion mutant, and these genes have been used to normalize expression in $B$. cenocepacia in other studies. ${ }^{62,63}$

\section{Protein expression and purification}

FixL and FixJ expression vectors were transformed into E. coli BL21 DE3 cells and protein was expressed and purified using nickel affinity columns following published protocols. $^{52}$ 


\section{In vitro phosphorylation}

Autophosphorylation and phosphotransfer assays were done as previously described. ${ }^{64}$ Briefly, FixL variants were used at a final concentration of $2.5 \mu \mathrm{M}$ mixed with a final concentration of $5 \mathrm{mM} \mathrm{MgCl}_{2}, 0.5 \mathrm{mM}$ ATP, and $2.5 \mu \mathrm{Ci}$ of $\left[\gamma^{32} \mathrm{P}\right]$-ATP (stock of 6000 $\mathrm{Ci} / \mathrm{mmol} 10 \mathrm{mCi} / \mathrm{mL}$, from Perkin Elmer). Autophosphorylation reactions were performed at $30{ }^{\circ} \mathrm{C}$, ambient oxygen, and stopped at the indicated time points by the addition of 4x sample buffer (200 mM Tris-Cl at pH 6.8, $400 \mathrm{mM}$ DTT, 8\% SDS, 0.4\% bromophenol blue, $40 \%$ glycerol). For phosphotransfer assays, FixL variants were autophosphorylated using the above parameters at $30^{\circ} \mathrm{C}$ for 15 minutes and then incubated with reactions containing the response regulator FixJ and $\mathrm{MgCl}_{2}$ at final concentrations of $5 \mu \mathrm{M}$ and $5 \mathrm{mM}$, respectively. Phosphotransfer reactions were run at 30 ${ }^{\circ} \mathrm{C}$ and ambient oxygen. Reactions were stopped at the indicated time points with the addition of 4x sample buffer. Samples were then run on an "any kD" BioRad miniprotean TGX gel for 50 minutes at $150 \mathrm{~V}$. Gels were exposed to phosphor-screens for 4-5 hours so that phosphorylated protein bands could be observed. Screens were imaged using the Typhoon-FLA9500 imager with a "phosphor" setting and a resolution of 50 $\mu \mathrm{m}$. Band intensity of phosphorylated proteins was quantified using ImageJ.

\section{Reporter assay}

BCC carrying a fixK-lacZ report plasmid were grown overnight in LB with kanamycin (1 $\mathrm{mg} / \mathrm{mL}$ ). Cultures were subcultured in LB in ambient oxygen or LB that had been degassed in CampyGen Gas Generating System (Thermo-Fisher). Cultures were grown in ambient oxygen with shaking (200 rpm) at $37^{\circ} \mathrm{C}$ or within CampyGen Gas Generating System at $37^{\circ} \mathrm{C}$ for $4-6$ hours. The level of fix pathway-driven LacZ activity was measured by determining Miller Units following published procedures. ${ }^{65}$

\section{c-di-GMP quantification}

B. dolosa constructs were grown to stationary phase when $50 \mathrm{~mL}$ aliquots were spun down and c-di-GMP was extracted using ice-cold extraction buffer (methanol:acetonitrile: $\mathrm{dH}_{2} \mathrm{O}$ 40:40:20 + 0.1 N formic acid). c-di-GMP levels were measured using mass spectroscopy as previously described. ${ }^{66}$

\section{Data availability}

RNA-seq reads have been deposited to BioProject PRJNA579568 https://www.ncbi.nlm.nih.gov/bioproject/579568.

\section{Acknowledgments}

The authors would like acknowledge Brian Hsueh and Christopher Waters (Michigan State University) for measurement of c-di-GMP. This work was funded by the Cystic Fibrosis Foundation (PRIEBE13I0 to GPP) and the National Institutes of Health (R01GM110444 to VSC) and, in part, by the Richard A. and Susan F. Smith President's Innovation Award (no number, to GPP) and by funds from the Translational Research for Infection Prevention in Pediatric Anesthesia and Critical Care (TRIPPACC) Program of the Department of Anesthesiology, Critical Care and Pain Medicine at Boston Children's Hospital (no number, to GPP). 
1 Gibson, R. L., Burns, J. L. \& Ramsey, B. W. (2003). Pathophysiology and management of pulmonary infections in cystic fibrosis. Am. J. Respir. Crit. Care Med. 168, 918-951.

2 Mahenthiralingam, E., Urban, T. A. \& Goldberg, J. B. (2005). The multifarious, multireplicon Burkholderia cepacia complex. Nat Rev Microbiol 3, 144-156.

3 LiPuma, J. J. (2003). Burkholderia and emerging pathogens in cystic fibrosis. Semin Resp Crit Care Med 24, 681-692.

4 Zlosnik, J. E., Zhou, G., Brant, R., Henry, D. A., Hird, T. J., Mahenthiralingam, E., Chilvers, M. A., Wilcox, P. \& Speert, D. P. (2015). Burkholderia species infections in patients with cystic fibrosis in British Columbia, Canada. 30 years' experience. Ann Am Thorac Soc 12, 70-78.

5 Lipuma, J. J. (2010). The changing microbial epidemiology in cystic fibrosis. Clin Microbiol Rev 23, 299-323.

6 Govan, J. R., Brown, A. R. \& Jones, A. M. (2007). Evolving epidemiology of Pseudomonas aeruginosa and the Burkholderia cepacia complex in cystic fibrosis lung infection. Future Microbiol 2, 153-164.

7 Pope, C. E., Short, P. \& Carter, P. E. (2010). Species distribution of Burkholderia cepacia complex isolates in cystic fibrosis and non-cystic fibrosis patients in New Zealand. J Cyst Fibros 9, 442-446.

8 Biddick, R., Spilker, T., Martin, A. \& LiPuma, J. J. (2003). Evidence of transmission of Burkholderia cepacia, Burkholderia multivorans and Burkholderia dolosa among persons with cystic fibrosis. FEMS microbiology letters 228, 57-62.

9 Blanchard, A. C., Tadros, M., Tang, L., Muller, M., Spilker, T., Waters, V., Lipuma, J. \& Tullis, E. (2018). 1256. New Acquisitions of ET-12 Burkholderia cenocepacia in Adults With Cystic Fibrosis: Role of Whole Genome Sequencing in Outbreak Investigation. Open Forum Infectious Diseases 5, S383-S383.

10 Roos, D. (2016). Chronic granulomatous disease. Br Med Bull 118, 50-63.

11 Dolan, S. A., Dowell, E., LiPuma, J. J., Valdez, S., Chan, K. \& James, J. F. (2011). An outbreak of Burkholderia cepacia complex associated with intrinsically contaminated nasal spray. Infect Control Hosp Epidemiol 32, 804810.

12 Souza Dias, M. B., Cavassin, L. G., Stempliuk, V., Xavier, L. S., Lobo, R. D., Sampaio, J. L., Pignatari, A. C., Borrasca, V. L., Bierrenbach, A. L. \& Toscano, C. M. (2013). Multi-institutional outbreak of Burkholderia cepacia complex associated with contaminated mannitol solution prepared in compounding pharmacy. Am J Infect Control 41, 1038-1042.

13 Vardi, A., Sirigou, A., Lalayanni, C., Kachrimanidou, M., Kaloyannidis, P., Saloum, R., Anagnostopoulos, A. \& Sotiropoulos, D. (2013). An outbreak of Burkholderia cepacia bacteremia in hospitalized hematology patients selectively affecting those with acute myeloid leukemia. Am J Infect Control 41, 312-316.

14 Antony, B., Cherian, E. V., Boloor, R. \& Shenoy, K. V. (2016). A sporadic outbreak of Burkholderia cepacia complex bacteremia in pediatric intensive care unit of a tertiary care hospital in coastal Karnataka, South India. Indian J Pathol Microbiol 59, 197-199. 
15 Glowicz, J., Crist, M., Gould, C., Moulton-Meissner, H., Noble-Wang, J., de Man, T. J. B., Perry, K. A., Miller, Z., Yang, W. C., Langille, S., Ross, J., Garcia, B., Kim, J., Epson, E., Black, S., Pacilli, M., LiPuma, J. J., Fagan, R. \& Workgroup, B. c. I. (2018). A multistate investigation of health care-associated Burkholderia cepacia complex infections related to liquid docusate sodium contamination, January-October 2016. Am J Infect Control.

16 Marquez, L., Jones, K. N., Whaley, E. M., Koy, T. H., Revell, P. A., Taylor, R. S., Bernhardt, M. B., Wagner, J. L., Dunn, J. J., LiPuma, J. J. \& Campbell, J. R. (2017). An outbreak of Burkholderia cepacia complex infections associated with contaminated liquid docusate. Infect Control Hosp Epidemiol, 1-7.

17 Lieberman, T. D., Flett, K. B., Yelin, I., Martin, T. R., McAdam, A. J., Priebe, G. P. \& Kishony, R. (2014). Genetic variation of a bacterial pathogen within individuals with cystic fibrosis provides a record of selective pressures. Nature genetics 46, 82-87.

18 Lieberman, T. D., Michel, J. B., Aingaran, M., Potter-Bynoe, G., Roux, D., Davis, M. R., Jr., Skurnik, D., Leiby, N., Lipuma, J. J., Goldberg, J. B., McAdam, A. J., Priebe, G. P. \& Kishony, R. (2011). Parallel bacterial evolution within multiple patients identifies candidate pathogenicity genes. Nature genetics 43, 1275-1280.

19 Silva, I. N., Santos, P. M., Santos, M. R., Zlosnik, J. E. A., Speert, D. P., Buskirk, S. W., Bruger, E. L., Waters, C. M., Cooper, V. S. \& Moreira, L. M. (2016). Long-term evolution of Burkholderia multivorans during a chronic cystic fibrosis infection reveals shifting forces of selection. mSystems 1, e00029-00016.

20 Schaefers, M. M. (2020). Regulation of Virulence by Two-component Systems in Pathogenic Burkholderia. Infect. Immun.

21 Schaefers, M. M., Liao, T. L., Boisvert, N. M., Roux, D., Yoder-Himes, D. \& Priebe, G. P. (2017). An oxygen-sensing two-component system in the Burkholderia cepacia complex regulates biofilm, intracellular invasion, and pathogenicity. PLoS Pathog 13, e1006116.

22 Henry, J. T. \& Crosson, S. (2011). Ligand-binding PAS domains in a genomic, cellular, and structural context. Annual review of microbiology 65, 261-286.

23 Choi, K. H., DeShazer, D. \& Schweizer, H. P. (2006). mini-Tn7 insertion in bacteria with multiple glmS-linked att $\mathrm{Tn} 7$ sites: example Burkholderia mallei ATCC 23344. Nat Protoc 1, 162-169.

24 Lopez, C. M., Rholl, D. A., Trunck, L. A. \& Schweizer, H. P. (2009). Versatile dual-technology system for markerless allele replacement in Burkholderia pseudomallei. Appl Environ Microbiol 75, 6496-6503.

25 Valentini, M. \& Filloux, A. (2019). Multiple Roles of c-di-GMP Signaling in Bacterial Pathogenesis. Annual review of microbiology 73, 387-406.

26 Lee, H. S., Gu, F., Ching, S. M., Lam, Y. \& Chua, K. L. (2010). CdpA Is a Burkholderia pseudomalleiCyclic di-GMP Phosphodiesterase Involved in Autoaggregation, Flagellum Synthesis, Motility, Biofilm Formation, Cell Invasion, and Cytotoxicity. Infection and immunity 78, 1832.

27 Richter, A. M., Fazli, M., Schmid, N., Shilling, R., Suppiger, A., Givskov, M., Eberl, L. \& Tolker-Nielsen, T. (2019). Key Players and Individualists of Cyclicdi-GMP Signaling in Burkholderia cenocepacia. Frontiers in Microbiology 9. 
28 Kumar, B. \& Cardona, S. T. (2016). Synthetic Cystic Fibrosis Sputum Medium Regulates Flagellar Biosynthesis through the flhF Gene in Burkholderia cenocepacia. Frontiers in cellular and infection microbiology 6, 65.

29 Urban, T. A., Griffith, A., Torok, A. M., Smolkin, M. E., Burns, J. L. \& Goldberg, J. B. (2004). Contribution of Burkholderia cenocepacia flagella to infectivity and inflammation. Infection and immunity 72, 5126-5134.

30 Saldías, M. S., Lamothe, J., Wu, R. \& Valvano, M. A. (2008). Burkholderia cenocepacia requires the RpoN sigma factor for biofilm formation and intracellular trafficking within macrophages. Infection and immunity 76, 10591067.

31 Tomich, M., Herfst, C. A., Golden, J. W. \& Mohr, C. D. (2002). Role of flagella in host cell invasion by Burkholderia cepacia. Infection and immunity 70, 17991806.

32 Fazli, M., Rybtke, M., Steiner, E., Weidel, E., Berthelsen, J., Groizeleau, J., Bin, W., Zhi, B. Z., Yaming, Z., Kaever, V., Givskov, M., Hartmann, R. W., Eberl, L. \& Tolker-Nielsen, T. (2017). Regulation of Burkholderia cenocepacia biofilm formation by RpoN and the c-di-GMP effector BerB. Microbiologyopen 6 , e00480.

33 Cunha, M. V., Sousa, S. A., Leitao, J. H., Moreira, L. M., Videira, P. A. \& SaCorreia, I. (2004). Studies on the involvement of the exopolysaccharide produced by cystic fibrosis-associated isolates of the Burkholderia cepacia complex in biofilm formation and in persistence of respiratory infections. Journal of clinical microbiology 42, 3052-3058.

34 Skurnik, D., Davis, M. R., Jr., Benedetti, D., Moravec, K. L., Cywes-Bentley, C., Roux, D., Traficante, D. C., Walsh, R. L., Maira-Litran, T., Cassidy, S. K., Hermos, C. R., Martin, T. R., Thakkallapalli, E. L., Vargas, S. O., McAdam, A. J., Lieberman, T. D., Kishony, R., Lipuma, J. J., Pier, G. B., Goldberg, J. B. \& Priebe, G. P. (2012). Targeting pan-resistant bacteria with antibodies to a broadly conserved surface polysaccharide expressed during infection. J Infect Dis 205, 1709-1718.

35 Fazli, M., McCarthy, Y., Givskov, M., Ryan, R. P. \& Tolker-Nielsen, T. (2013). The exopolysaccharide gene cluster Bcam1330-Bcam1341 is involved in Burkholderia cenocepacia biofilm formation, and its expression is regulated by cdi-GMP and Bcam1349. Microbiologyopen 2, 105-122.

36 O'Rourke, D., FitzGerald, C. E., Traverse, C. C. \& Cooper, V. S. (2015). There and back again: consequences of biofilm specialization under selection for dispersal. Front Genet 6, 18-18.

37 Cooper, V. S., Staples, R. K., Traverse, C. C. \& Ellis, C. N. (2014). Parallel evolution of small colony variants in Burkholderia cenocepacia biofilms. Genomics 104, 447-452.

38 Schwab, U., Abdullah, L. H., Perlmutt, O. S., Albert, D., Davis, C. W., Arnold, R. R., Yankaskas, J. R., Gilligan, P., Neubauer, H., Randell, S. H. \& Boucher, R. C. (2014). Localization of Burkholderia cepacia complex bacteria in cystic fibrosis lungs and interactions with Pseudomonas aeruginosa in hypoxic mucus. Infection and immunity 82, 4729-4745. 
39 Zlosnik, J. E., Costa, P. S., Brant, R., Mori, P. Y., Hird, T. J., Fraenkel, M. C., Wilcox, P. G., Davidson, A. G. \& Speert, D. P. (2011). Mucoid and nonmucoid Burkholderia cepacia complex bacteria in cystic fibrosis infections. Am J Respir Crit Care Med 183, 67-72.

40 Winstanley, C., O'Brien, S. \& Brockhurst, M. A. (2016). Pseudomonas aeruginosa Evolutionary Adaptation and Diversification in Cystic Fibrosis Chronic Lung Infections. Trends in microbiology 24, 327-337.

41 Kalferstova, L., Kolar, M., Fila, L., Vavrova, J. \& Drevinek, P. (2015). Gene expression profiling of Burkholderia cenocepacia at the time of cepacia syndrome: loss of motility as a marker of poor prognosis? Journal of clinical microbiology 53, 1515-1522.

42 Price, E. P., Viberg, L. T., Kidd, T. J., Bell, S. C., Currie, B. J. \& Sarovich, D. S. (2018). Transcriptomic analysis of longitudinal Burkholderia pseudomallei infecting the cystic fibrosis lung. Microb Genom 4, e000194.

43 Tognon, M., Köhler, T., Luscher, A. \& van Delden, C. (2019). Transcriptional profiling of Pseudomonas aeruginosa and Staphylococcus aureus during in vitro co-culture. BMC Genomics 20, 30-30.

44 Ma, L., Conover, M., Lu, H., Parsek, M. R., Bayles, K. \& Wozniak, D. J. (2009). Assembly and Development of the Pseudomonas aeruginosa Biofilm Matrix. PLOS Pathogens 5, e1000354.

45 Hauser, A. R., Jain, M., Bar-Meir, M. \& McColley, S. A. (2011). Clinical Significance of Microbial Infection and Adaptation in Cystic Fibrosis. Clinical microbiology reviews 24, 29.

46 Malhotra, S., Hayes, D. \& Wozniak, D. J. (2019). Cystic Fibrosis and Pseudomonas aeruginosa: the Host-Microbe Interface. Clinical microbiology reviews 32, e00138-00118.

47 Winstanley, C., O'Brien, S. \& Brockhurst, M. A. (2016). Pseudomonas aeruginosa Evolutionary Adaptation and Diversification in Cystic Fibrosis Chronic Lung Infections. Trends Microbiol 24, 327-337.

48 Lee, A. H.-Y., Flibotte, S., Sinha, S., Paiero, A., Ehrlich, R. L., Balashov, S., Ehrlich, G. D., Zlosnik, J. E. A., Mell, J. C. \& Nislow, C. (2017). Phenotypic diversity and genotypic flexibility of Burkholderia cenocepacia during long-term chronic infection of cystic fibrosis lungs. Genome Research.

49 Choi, K.-H., Mima, T., Casart, Y., Rholl, D., Kumar, A., Beacham, I. R. \& Schweizer, H. P. (2008). Genetic tools for select-agent-compliant manipulation of Burkholderia pseudomallei. Applied and Environmental Microbiology 74, 1064 1075.

50 Choi, K. H. \& Schweizer, H. P. (2006). mini-Tn7 insertion in bacteria with single attTn7 sites: example Pseudomonas aeruginosa. Nat Protoc 1, 153-161.

51 Cardona, S. T. \& Valvano, M. A. (2005). An expression vector containing a rhamnose-inducible promoter provides tightly regulated gene expression in Burkholderia cenocepacia. Plasmid 54, 219-228.

52 Skerker, J. M., Prasol, M. S., Perchuk, B. S., Biondi, E. G. \& Laub, M. T. (2005). Two-Component Signal Transduction Pathways Regulating Growth and Cell Cycle Progression in a Bacterium: A System-Level Analysis. PLOS Biology 3, e334. 
53 Merritt, J. H., Kadouri, D. E. \& O'Toole, G. A. (2005). Growing and analyzing static biofilms. Curr Protoc Microbiol Chapter 1, Unit 1B.1.

54 Zlosnik, J. E., Mori, P. Y., To, D., Leung, J., Hird, T. J. \& Speert, D. P. (2014). Swimming motility in a longitudinal collection of clinical isolates of Burkholderia cepacia complex bacteria from people with cystic fibrosis. PLoS One 9, e106428.

55 Afgan, E., Baker, D., van den Beek, M., Blankenberg, D., Bouvier, D., Čech, M., Chilton, J., Clements, D., Coraor, N., Eberhard, C., Grüning, B., Guerler, A., Hillman-Jackson, J., Von Kuster, G., Rasche, E., Soranzo, N., Turaga, N., Taylor, J., Nekrutenko, A. \& Goecks, J. (2016). The Galaxy platform for accessible, reproducible and collaborative biomedical analyses: 2016 update. Nucleic acids research 44, W3-W10.

56 Bolger, A. M., Lohse, M. \& Usadel, B. (2014). Trimmomatic: a flexible trimmer for Illumina sequence data. Bioinformatics (Oxford, England) 30, 2114-2120.

57 Johnson, S. L., Bishop-Lilly, K. A., Ladner, J. T., Daligault, H. E., Davenport, K. W., Jaissle, J., Frey, K. G., Koroleva, G. I., Bruce, D. C., Coyne, S. R., Broomall, S. M., Li, P.-E., Teshima, H., Gibbons, H. S., Palacios, G. F., Rosenzweig, C. N., Redden, C. L., Xu, Y., Minogue, T. D. \& Chain, P. S. (2015). Complete genome sequences for 59 Burkholderia isolates, both pathogenic and near neighbor. Genome Announcements 3, e00159-00115.

58 Langmead, B. \& Salzberg, S. L. (2012). Fast gapped-read alignment with Bowtie 2. Nat Meth 9, 357-359.

59 Trapnell, C., Williams, B. A., Pertea, G., Mortazavi, A., Kwan, G., van Baren, M. J., Salzberg, S. L., Wold, B. J. \& Pachter, L. (2010). Transcript assembly and quantification by RNA-Seq reveals unannotated transcripts and isoform switching during cell differentiation. Nat Biotech 28, 511-515.

60 Young, M. D., Wakefield, M. J., Smyth, G. K. \& Oshlack, A. (2010). Gene ontology analysis for RNA-seq: accounting for selection bias. Genome Biology 11, R14.

61 Livak, K. J. \& Schmittgen, T. D. (2001). Analysis of relative gene expression data using real-time quantitative PCR and the 2(-Delta Delta C(T)) Method. Methods 25, 402-408.

62 Schmid, N., Pessi, G., Deng, Y., Aguilar, C., Carlier, A. L., Grunau, A., Omasits, U., Zhang, L.-H., Ahrens, C. H. \& Eberl, L. (2012). The AHL- and BDSFdependent quorum sensing systems control specific and overlapping sets of genes in Burkholderia cenocepacia H111. PLoS ONE 7, e49966.

63 Ferreira, A. S., Leitão, J. H., Silva, I. N., Pinheiro, P. F., Sousa, S. A., Ramos, C. G. \& Moreira, L. M. (2010). Distribution of cepacian biosynthesis genes among environmental and clinical Burkholderia strains and role of cepacian exopolysaccharide in resistance to stress conditions. Applied and Environmental Microbiology 76, 441-450.

64 Laub, M. T., Biondi, E. G. \& Skerker, J. M. in Methods in Enzymology Vol. 423 (eds Melvin I. Simon, Brian R. Crane, \& Alexandrine Crane) 531-548 (Academic Press, 2007).

65 Saito, K., Ito, E., Hosono, K., Nakamura, K., Imai, K., Iizuka, T., Shiro, Y. \& Nakamura, H. (2003). The uncoupling of oxygen sensing, phosphorylation 
signalling and transcriptional activation in oxygen sensor FixL and FixJ mutants. Molecular microbiology 48, 373-383.

66 Waldron, E. J., Snyder, D., Fernandez, N. L., Sileo, E., Inoyama, D., Freundlich, J. S., Waters, C. M., Cooper, V. S. \& Neiditch, M. B. (2019). Structural basis of DSF recognition by its receptor RpfR and its regulatory interaction with the DSF synthase RpfF. PLOS Biology 17, e3000123.

67 Letunic, I., Doerks, T. \& Bork, P. (2015). SMART: recent updates, new developments and status in 2015. Nucleic acids research 43, D257-D260. 
a

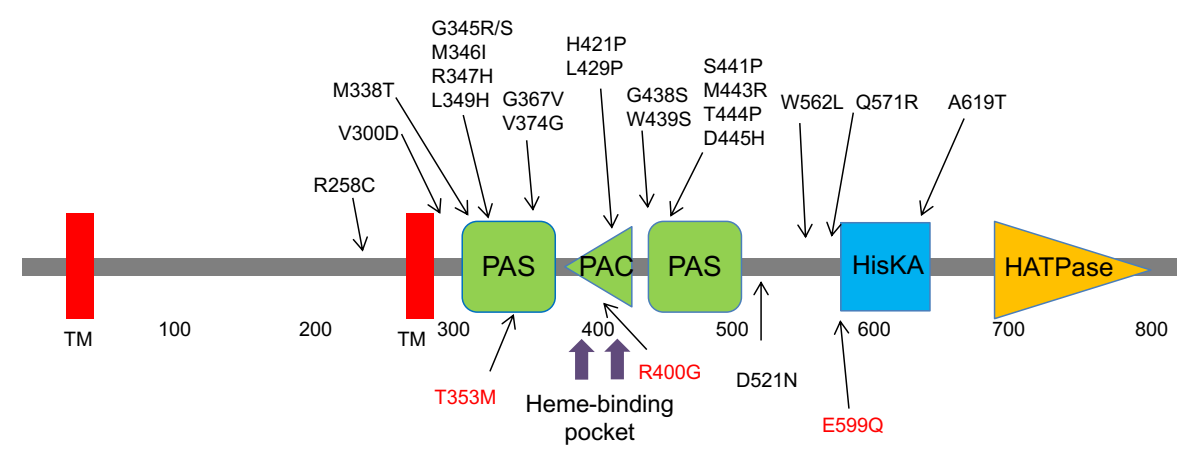

$\mathrm{b}$



Days after first $B$. dolosa isolate

Figure 1. Mutations in the Burkholderia dolosa FixL sensory domain are associated with decline in lung function in cystic fibrosis. a. Domains predicted by SMART ${ }^{65}$ and observed SNPs in B. dolosa in black ${ }^{17,18}$ and $B$. multivorans in red. ${ }^{19}$ Domain abbreviations: TM, transmembrane; PAC, Motif Cterminal to PAS motif; HisKA, histidine kinase; HATPase, histidine kinaseassociated ATPase. b. Rapid decline in percent predicted FEV1 (ppFEV1) in a CF patient (Patient $L$ ) after detection of mutations in the sensory domain (PAS) of FixL. Downward arrows denote sequenced isolates from patient $\mathrm{M}$, upward arrows denote sequenced isolates from patient $\mathrm{L}$. Purple arrow: ancestral fix $\mathrm{L}$ allele; red arrow: fix $L$ mutation in sensory domain; green arrow: fix $L$ mutation not in sensory domain. $\mathrm{P}=0.05$ by linear regression, comparing ppFEV1 slopes before and after detection of fixL mutations in sensory domain (red arrows). 
a

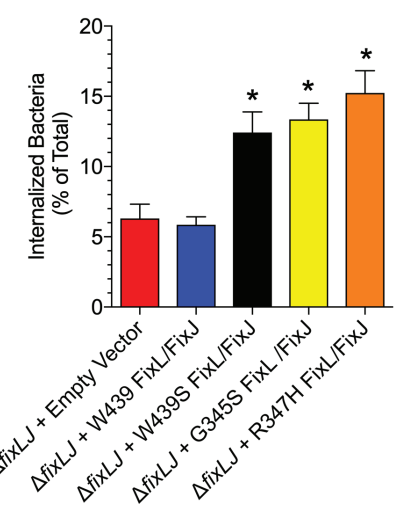

C

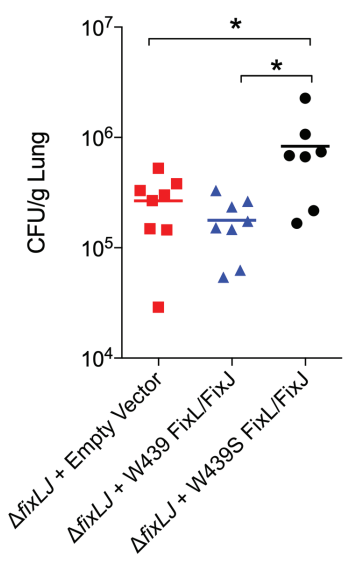

b

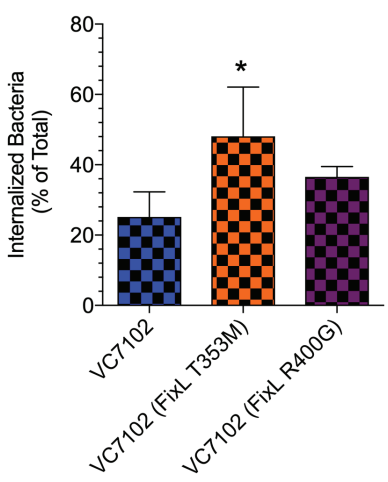

d

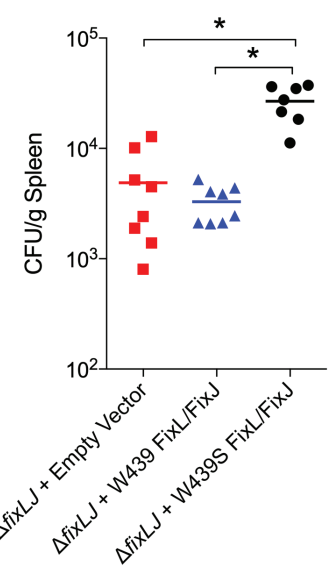



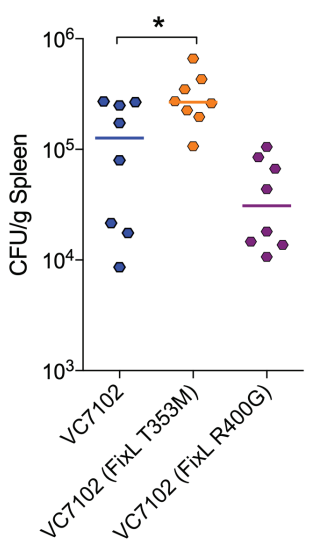



Figure 2. Burkholderia cepacia complex strains carrying evolved FixL variants are more virulent in human macrophages and a murine pneumonia model but less able to survive within soil. PMA-treated THP-1 human macrophages were infected with $\sim 2 \times 106$ CFU/well (MOI of $\sim 10: 1$ ) of (a) $B$. dolosa strain AU0158 or (b) B. multivorans strain VC7102 isogenic constructs carrying FixL sequence variants for 2 hours, after which the percent of internalized bacterial relative to the total bacterial growth was determined by killing extracellular bacteria with kanamycin $(1 \mathrm{mg} / \mathrm{mL})$. Means from 2-3 separate experiments with three replicates per experiment are plotted with error bars representing one standard deviation. ${ }^{*} \mathrm{P}<0.05$ by ANOVA with Tukey's multiple comparison test compared to (a) $\Delta$ fix $L J+$ empty vector and $\triangle$ fixLJ + W439 FixL/FixJ or (b) strain VC7102. C57BL/6 mice were intranasally challenged with $\sim 4 \times 10^{8} \mathrm{CFU} /$ mouse of (c) B. dolosa strain AU0158 or (d) B. multivorans strain VC7102 isogenic constructs carrying FixL sequence variants. Bacterial loads were measured in the lungs and spleen 7 days after infection. Data are representative of 2 separate experiments with 7-8 mice per group. Each point represents one mouse, and bars represent medians. ${ }^{*} \mathrm{P}<0.05$ by ANOVA with Tukey's multiple comparison test. (e) B. dolosa strain AU0158 $\triangle$ fix LJ mutant complemented with fixLJ isogenic constructs or empty vector were inoculated into $1 \mathrm{~g}$ sterile soil (1-6 $\times 10^{6} \mathrm{CFU}$ in minimal media) and incubated for 10 days. Bacterial load was measured and plotted relative to the inoculum used. ${ }^{*} \mathrm{P}<0.05$ compared to W439 by ANOVA with Tukey's multiple comparison test. 
bioRxiv preprint doi: https://doi.org/10.1101/2020.05.04.070367; this version posted May 5, 2020. The copyright holder for this preprint (which was not certified by peer review) is the author/funder, who has granted bioRxiv a license to display the preprint in perpetuity. It is made

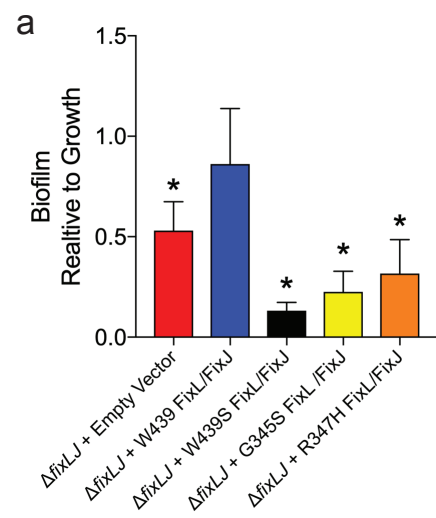

C

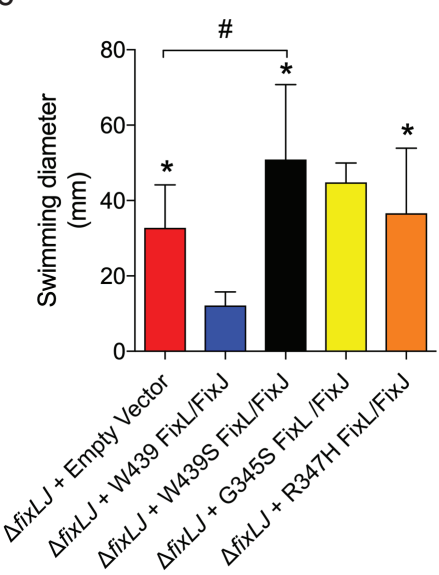

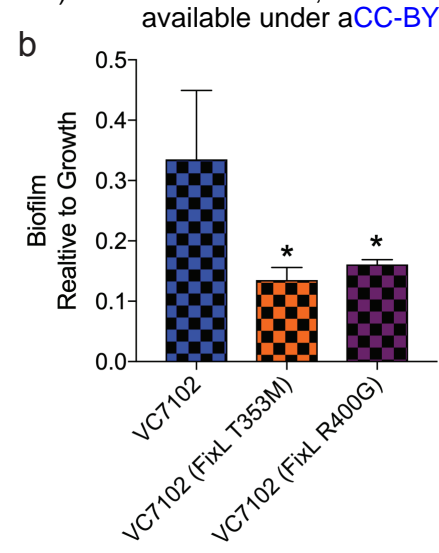

d

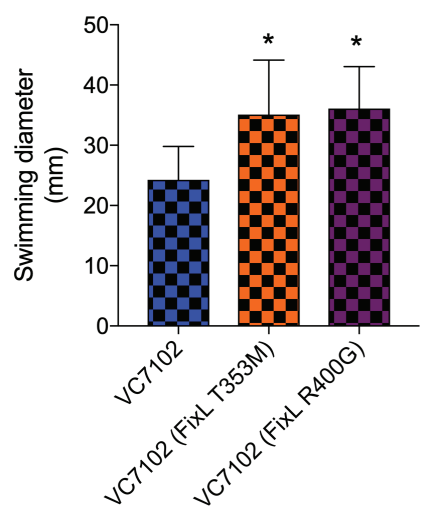

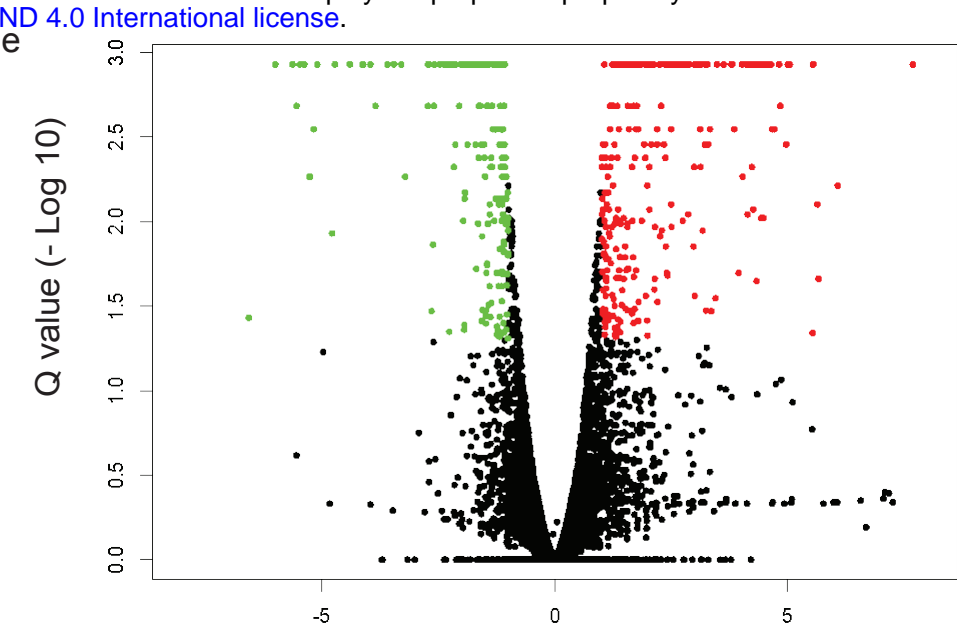

Fold Change in W439S vs W439 (Log2)

$\mathrm{f}$

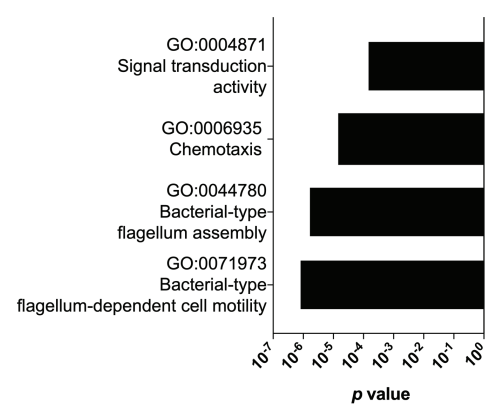

Figure 3. Burkholderia cepacia complex strains carrying evolved FixL variants are more motile, make less biofilm, and have altered gene expression. Biofilm formation of (a) B. dolosa strain AU0158 or (b) B. multivorans strain VC7102 isogenic constructs carrying FixL sequence variants on PVC plates as measured by crystal violet staining at 48 hours. Means from 3 separate experiments with 5-6 replicates per experiment are plotted with error bars representing one standard deviation. ${ }^{*} \mathrm{P}<0.05$ by ANOVA with Tukey's multiple comparison test to $\triangle$ fixLJ+W439 FixL/ FixJ or VC7102. Motility of (C) B. dolosa strain AU0158 or (D) B. multivorans strain VC7102 isogenic constructs carrying FixL sequence variants on low-density (0.3\%) LB agar and swimming distance was measured after incubation for 48 hours. Means from 3 separate experiments with 3-4 replicates per experiment are plotted with error bars representing one standard deviation. * $\mathrm{P}<0.05$ by ANOVA with Tukey's multiple comparison test compared to construct carrying ancestral FixL variant (W439 or VC7102); \#P<0.05 by ANOVA with Tukey's multiple comparison test. (E) Volcano plot depicting the differential regulation of genes. Green dots signify genes with expression 2-fold lower in the B. dolosa strain AU0158 construct carrying the ancestral FixL variant (W439) relative to a construct carrying the evolved variant (W439S), with a $q<0.05$. Red dots signify genes with expression 2 -fold higher in the evolved variant (W439S) construct carrying the relative to a construct carrying the ancestral FixL variant (W439), with a $q<0.05$. (F) GO terms that were enriched with an adjusted $p$ value $<0.05$ among genes that were statistically upregulated ( $q$ value $<0.05$, at least 2-fold) in $B$. dolosa carrying the evolved FixL variant (W439S) relative to $B$. dolosa carrying the ancestral FixL variant. 


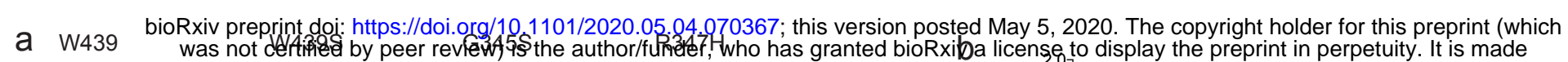

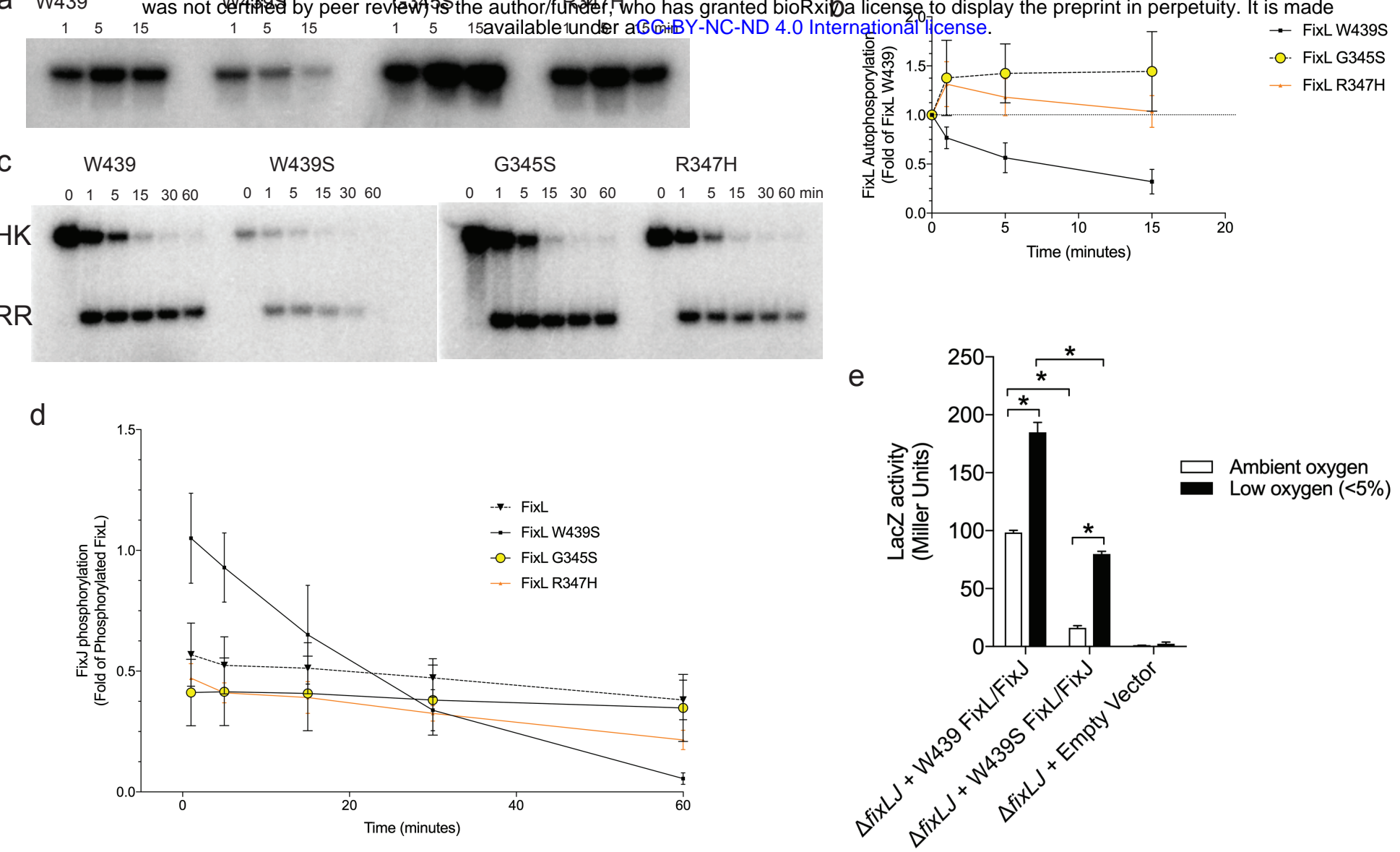

Figure 4. Evolved FixL variants have different mechanism of down regulating fix pathway phosphorylation. (A) Representative plots of autophosphorylation of $B$. dolosa FixL variants. (B) Density measurements from 3 independent experiments were normalized relative W439 at the same time point. ${ }^{*} \mathrm{P}<0.05$ compared to $\mathrm{W} 439$ at the same time point by $t$ test. (C) Representative plots of phospho-transfer to FixJ of $B$. dolosa FixL variants. (D) Density measurements from 3 independent experiments were normalized based on level the level of FixL phosphorylation at time 0 for each construct. ${ }^{*} \mathrm{P}<0.05$ compared to W439 at the same time point by $t$ test. (E) B. dolosa strain AU0158 constructs carrying FixL sequence variants or an empty vector carrying a pfixK-lacZ reporter plasmid21 grown in ambient or low $(<5 \%)$ oxygen. Bars represent the means of triplicate biological replicates, and error bars represent one standard deviation (representative of three independent experiments). ${ }^{*} \mathrm{P}<0.05$ by ANOVA with Tukey's multiple comparison test. 